\title{
The Moderating Effect of Family Health in the Impact of COVID-19 Anxiety on Life Satisfaction
}

\section{코로나 불안감이 삶 만족도에 미치는 영향에서 가족 건강성의 조절효과}

Min Jung $\mathrm{Kim}^{1}$, Yun-Jeong $\mathrm{Kim}^{2}$

김민정 ${ }^{1}$, 김윤정 ${ }^{2}$

${ }^{1}$ Center Director, Dangjin Healthy Family Support Center, Republic of Korea, kimmjsss@hanmail.net

${ }^{2}$ Professor, Dept. of Health, Counselling and Welfare, Hanseo Uinversity, Republic of Korea, twoyun21@hanmail.net

Corresponding author: Yun-Jeong Kim

\begin{abstract}
The purpose of this study is to verify the moderating effect of family strength in the effect of COVID-19 anxiety on life satisfaction in the COVID-19 pandemic situation. To this end, 216 copies of adult female responses from the data from the "2020 Dangin City Family Survey" were used. Moderating effect analysis was conducted by applying SPSS 24.0 version and SPSS PROCESS MACRO No. 1 model. The results of the study are as follows: First, overall, the group with high family strength had higher satisfaction with life than the group with low family strength. Second, in the case of a group with high family resilience, family intimacy, and family economic stability, the negative influence of COVID-19 anxiety on life satisfaction was found to be greater. In other words, it was found that the negative impact of COVID-19 anxiety on the quality of life is rather reinforced when family resilience, family intimacy family economic stability are high. Third, the negative impact of COVID-19 anxiety on life satisfaction in families with high family culture and social participation was buffered by family culture and social participation. Based on the results of this study, the importance of the family's social community consciousness was suggested.
\end{abstract}

Keywords: COVID-19, COVID-19 Anxiety, Family Strength, Moderating Effect

요약: 본 연구는 코로나 19 팬데믹으로 인한 코로나 불안감이 삶의 만족도에 미치는 영향에서 가족건강성의 조절효과를 파악하는데 목적이 있다. 이를 위해 '2020년 당진시 가족실태조사' 의 데이터 중 성인 여성의 응답 216 부를 활용하였다. SPSS 24.0 version 과 SPSS PROCESS MACRO 1 번 모델을 적용하여 조절효과 분석을 실시하였다. 연구결과, 첫째, 전반적으로 가족건강성이 높은 집단이 낮은 집단에 비해 살의 만족도가 높았다. 둘째, 가족탄력성과 가족친밀감, 가족경제적 안정이 높은 집단일 경우, 코로나 불안감이 삶 만족도에 미치는 부정적인 영향력이 더 커지는 것으로 나타났다. 즉, 코로나 불안감이 삶의 질에 미치는 부정적 영향이 가족탄력성, 가족친말감 및 가족경제적 안정감이 높을 때, 오히려 더 강화되는 것으로 나타났다. 셋째, 가족문화와 사회참여가

Received: June 07, 2021; $1^{\text {st }}$ Review Result: July 23, 2021; $2^{\text {nd }}$ Review Result: September 09, 2021 Accepted: October 31, 2021 
높은 집단의 코로나 불안감이 삶 만족도에 미치는 부정적 영향은 가족문화와 사회참여로 완화되었다. 본 연구결과를 근거로 하여 가족의 사회공동체 의식의 중요성을 제안하였다.

핵심어: 코로나 19 , 코로나 불안감, 가족건강성, 삶 만족도, 조절효과

\section{1. 서론}

2020년 코로나 19의 세계적 확산은 우리의 일상에 많은 변화를 가져왔다. 현재 코로나는 팬데믹으로 불리우고 '코로나 블루' 라는 신조어가 생길 정도로[1], 우리 사회에 불안감과 우울감을 가중하고 있다. 개인과 가족은 코로나의 확산으로 인하여 사회적 단절과 고립을 경험하고 이는 개인의 스트레스, 불안, 우울, 두려움, 분노, 외로움, 좌절감, 슬픔 등 다양한 심리적 문제를 야기하고 있다[2]. 경기연구원에서 발표한 2021년 1분기 '국민 정신건강 실태조사' 에 따르면, 코로나 19로 인하여 불안과 우울감을 호소하는 국민은 지난해 조사결과보다 $8.3 \%$ 상승한 $55.8 \%$ 에 달했으며, 특히 우울증과 불안장애 질환으로 정신과 진료가 필요한 국민은 각각 $17.7 \%$ 와 $12.7 \%$, 자살을 생각한 국민은 $8.3 \%$ 에 달했다[3]. 국외에서도 이탈리아 성인의 $21 \%$ 가 심각한 수준 이상의 불안감을 경험하였고[4]. 오스트리아인의 $19 \%$ 가 코로나 19 시기 동안 중도 수준 이상의 불안감을 경험한 것으로 나타났다[5]. 따라서 본 연구에서는 코로나 19로 인한 불안감에 연구의 주된 초점을 두었다.

불안감 등의 부적 정서는 삶의 만족을 저하하는 요인이다. 특히 코로나 19 팬데믹 상황과 같은 과도한 공포와 관련된 사회불안감의 부적 정서는 삶의 기능적 측면을 손상시켜, 학업과 직장, 결혼 등 생활전반에서의 어려움을 격게 함으로써 삶의 만족을 크게 떨어뜨리고 있다. 신종전염병과 심리정서와 관련된 이전 연구들은 신종전염병으로 인한 스트레스가 일상생활에서 경험하는 스트레스보다 더 심각하고 광범위하게 개인의 삶의 질에 부정적인 영향을 미친다고 보고하였다[6][7].

한편, 삶의 질에 대한 반응모델을 제시한 Sprangers와 Schwartz(1999)에 의하면 문제가 되는 상황에서 선행요인들(antecedents)과 기제들(mechanisms)은 함께 상호작용하여 내적 기준, 가치, 개념화 등의 변화를 만들고 이에 따라 삶의 질에 대한 인식을 변화시킬 수 있다고 하였다[8]. 기존의 연구들에 의하면 스트레스적 상황에 직면했다고 해서 모든 사람이 스트레스를 경험하는 것은 아니며, 스트레스와 적응 간의 관계에서 심리·사회적 변인들의 완충효과가 있음을 제시하였다[9]. 코로나 19 팬데믹처럼 불가피하게 외부적 상황으로 벌어지는 위기에는 가족들이 어떤 방식으로 반응하고 대처하느냐에 따라 가족에게 위기가 되는지 여부가 결정된다[10]. 따라서 코로나 불안감으로 삶의 질이 위협받는 상황에서 가족건강성은 삶의 질을 조절할 것으로 예측된다.

가족건강성 (family strength)이란 가족 개개인의 성장과 발달을 도모하고, 가족원 간 분명하고 긍정적인 의사소통을 하며, 유대와 결속을 도모하고, 가족 문제나 위기를 잘 해결하며, 가족 공통의 가치관과 규칙이 있는 가족을 말한다. 가족건강성이 높은 가족은 스트레스를 중재하고 위기를 극복하며 역경을 잘 견딜 수 있도록 대처와 적응을 할 수 있는 회복력이 높은 가족이다[11]. 01son과 Portner(1985) 역시 건강한 가족은 스트레스 사건과 가족의 문제에 효율적인 방식으로 대처 할 수 있고, 가족체계 내·외적으로 대처자원을 소유하고 활용할 수 있으며, 스트레스와 가족 문제를 효과적으로 극복 
함으로써 적절한 응집성, 적응성, 만족도를 유지할 수 있다고 밝혔다. 따라서, 코로나 불안감으로 삶의 질이 위협받는 상황에서 가족건강성은 긍정적인 역할을 할 것으로 예측된다.

그러나, 코로나 19 의 확산으로 많은 분야의 연구가 발표되었음에도 개인의 심리 - 정서적 변화에 가장 많은 영향을 미치는 가족건강성에 관한 연구는 아직 부족하다. 기존의 연구[10]는 주로 코로나 19 로 인한 돌봄이나 가사 노등의 증가를 젠더적 관점에서 접근하거나, 스트레스와 대처의 관점에서 접근하고 있으며, 가족생활과 관련한 빅데이터 분석 수준에 그치고 있다.

코로나 19 가 장기화될수록 만성스트레스로 이어질 위험이 증가하고[6], 우울과 같은 심리적인 문제가 가족의 삶을 저해할 수 있지만[7], 본 연구에서 관심을 갖는 코로나 불안감과 개인의 삶 만족도 간의 관련성, 그리고 이러한 관련성에서 개인과 가족차원을 포함한 스트레스 완충요인으로써 가족건강성의 조절효과에 관한 연구는 찾아보지 못하였다. 또한 코로나 19 는 지속적으로 사회 및 경제 전반에 영향을 미칠 것으로 예상되고 있는데, 이러한 변화가 가족에게 미치는 영향을 살펴본 연구도 부족한 상황이다. 더구나 코로나 19 라는 특수한 상황을 극복하기 위한 가족차원의 개입이 시급한 현시점에서 가족의 응집력을 높이고 코로나 불안감을 감소시킬 수 있는 전략적 가족복지 방안 마련을 위한 기초자료가 부족하다.

이에 본 연구에서는 코로나 불안감이 삶의 만족도에 미치는 영향에서 가족건강성의 조절효과를 파악하는데 연구의 목적이 있다. 이러한 본 연구의 결과는 포스트 코로나 시대 가족 정책의 패러다임을 설정하는 데 기여할 것이다.

\section{2. 연구방법}

\section{1 자료수집절차 및 연구대상의 특징}

[표 1] 연구대상의 사회인구학적 특성

[Table 1] Socio-demographic Characteristics of the Subject of Study ( $N=216)$

\begin{tabular}{|c|c|c|c|}
\hline \multicolumn{2}{|r|}{ 구분 } & 빈도(명) & 퍼센트 (\%) \\
\hline \multirow{4}{*}{ 연령 } & 10,20 대 & 28 & 13.0 \\
\hline & 30대 & 95 & 44.0 \\
\hline & 40대 & 73 & 33.8 \\
\hline & 50,60 대 & 20 & 9.3 \\
\hline \multirow{3}{*}{ 최종 학력 } & 초, 중졸 & 2 & .9 \\
\hline & 고졸 & 187 & 87.0 \\
\hline & 대졸 이상 & 26 & 12.1 \\
\hline \multirow{3}{*}{ 직업 } & 사무/전문/관리직 & 127 & 58.8 \\
\hline & 생산/기술/판매서비스/자영업 & 26 & 12.0 \\
\hline & 주부, 학생, 무직 & 63 & 29.2 \\
\hline \multirow{4}{*}{ 가족 구성 } & 1 인 가구 & 14 & 6.5 \\
\hline & 부부가구 & 13 & 6.0 \\
\hline & 부부와 자녀 가구 & 165 & 76.4 \\
\hline & 기타 가구(한부모, 3 세대 등) & 24 & 11.1 \\
\hline 자녀수 & 1명 & 61 & 28.4 \\
\hline
\end{tabular}




\begin{tabular}{c|c|c|c}
\hline \multirow{4}{*}{ 경제활동 } & 2명 & 107 & 49.8 \\
\cline { 2 - 4 } & 3 명 이상 & 25 & 11.6 \\
\cline { 2 - 4 } & 없음 & 22 & 10.2 \\
\cline { 2 - 4 } & 경제활동하지않음 & 14 & 6.5 \\
\cline { 2 - 4 } & 맞벌이 & 127 & 59.1 \\
\cline { 2 - 4 } & 남편만 경제활동 & 58 & 27.0 \\
\cline { 2 - 4 } & 부인만 경제활동 & 16 & 7.4 \\
\hline \multirow{3}{*}{ 월평균소득 } & 200만원 미만 & 14 & 6.6 \\
\cline { 2 - 4 } & 200만원 400만원 & 68 & 32.1 \\
\cline { 2 - 4 } & 400만원 500만원 & 43 & 20.3 \\
\cline { 2 - 4 } & 500만원 이상 & 87 & 41.0 \\
\hline
\end{tabular}

본 연구에서는 '2020 당진시 가족실태조사' [12] 데이터를 활용하였다. 당진시 건강가정 지원센터에서는 2020년 11월 23일부터 12월 12일까지 3주간 대면 설문조사를 실시하였다. 표집방법은 지역할당으로 당진시 14 개 읍·면·동 중 9 개 면 지역은 각 10 부, 2 개 읍과 3 개 동 지역은 각 20 부를 배포하고, 당진시건강가정지원센터 이용자 130 부를 추가로 배포하여, 총 320 부가 배포되어 회수된 303 부 중 설문에 부실하게 응답한 설문과 남성을 제외한 216 부를 분석에 활용하였다. 남성 응답자 수가 적어서 여성 응답자의 데이터만을 분석에 활용하였다.

연구의 대상자의 특징을 살펴보면, 30 대가 $44.0 \%$ 로 가장 많고, 40 대가 $33.8 \%$ 였다. 최종 학력은 고졸이 $87.0 \%$ 로 대다수였고, 직업 사무/전문/관리직이 $58.8 \%$ 였다. 부부와 자녀가구로 이루어진 핵가족이 $76.4 \%$ 였고, 자녀수는 2 명인 경우가 $49.8 \%$ 였다. 맞벌이를 하는 경우가 $59.1 \%$ 고, 월평균소득은 500 만원 이상인 경우가 $41.0 \%$ 로 가장 많고, 200 만 원에서 400 만원인 경우가 $32.1 \%$ 였다.

\section{2 측정도구}

\subsection{1 코로나 불안감}

코로나 불안감은 코로나로 인한 변화 문항 중 일부를 사용하였다. 코로나로 인한 변화는 선행연구[13-15]를 참고하여 10문항, 5점 리커트형(전혀 그렇지 않다 매우 그렇다) 척도로 구성하였다. 10 개 문항으로 요인분석을 실시하였는데, 요인추출은 Maximun Likelihood 방식을 취하였고 요인회전은 Varimax 방식을 적용하였다. Screeplot을 보고 요인수를 결정하였는데 전체 3 개의 요인이 추출되었다. 코로나 불안감 5 문항, 코로나 부담 5 문항이 도출되었고, 그 중에서 본 연구에서는 '코로나 불안감' 5 문항을 사용하였다. 점수가 높을수록 코로나 불안감이 높은 것이며, 불안감 척도의 신뢰도 cronbach's alpha값은 .823이다.

\subsection{2 가족건강성}

가족건강성을 측정하기 위해 유영주 외[16]가 개발한 '한국형 가족건강성 척도 II 를 사용하였다. 이 척도는 22 문항 5점 Likert 척도(전혀 그렇지 않다 매우 그렇다)로 가족탄력성 (7문항), 상호존중과 수용(5문항), 가족친밀감 (4문항), 가족경제적 안정 (3문항), 가족문화와 사회참여 (3문항)의 5 개의 하위요인으로 구성되어 있다. 전체 
가족건강성의 신뢰도 Cronbach's alpha값은 .940이고, 가족탄력성 .902, 가족친밀감 .852 , 가족존중 수용 .918 , 가족경제적 안정 .878 , 가족문화와 사회참여 .735 이다. 점수가 높을수록 가족탄력성, 가족친밀감, 가족존중수용, 가족경제적 안정, 가족문화와 사회참여가 높은 것을 의미한다. 가족건강성의 조절효과를 파악하기 위해서는 각 하위요인을 사용하였다. 단, 조절효과 분석에서 가족존중수용은 유의하지 않아 분석에서 제외하였다.

\subsection{3 삶 만족도}

Diener, Emmons, Larsen, Criffin[17]가 개발한 삶 만족도(Satisfaction with LifeScale) 측정도구를 사용하였다. 5개 문항, 5점 리커트형 척도(전혀 그렇지 않다 매우 그렇다)로써 점수가 높을수록 삶 만족도가 높음을 의미한다. 척도의 신뢰도 Cronbach' s alpha값은 .880이었다.

\section{3 통계분석방법}

SPSS 24.0 ver을 이용하여 빈도분석, 신뢰도 분석을 실시하였고, SPSS PROCESS MACRO 1 번 모델을 적용하여 조절효과분석을 실시하였다.

\section{3. 연구결과}

\section{1 코로나 불안감이 삶 만족도에 미치는 영향에서 가족탄력성의 조절효과}

가족탄력성이 코로나 불안감과 삶 만족도간의 관계를 조절하는지 분석한 결과, 코로나 불안감과 가족탄력성 상호작용항의 효과값이 -.160( $\mathrm{p}<.05)$ 로 유의미하였다. 또한 상호작용항이 추가됨에 따라 $\mathrm{R}^{2}$ 변화량은 .031( $\left.\mathrm{p}<.05\right)$ 로 유의미하여, 가족탄력성의 조절효과가 검증되었다[표 2]. 먼저 [표 2]의 조건부 효과를 보면, 가족탄력성의 세 가지 조건 $(\mathrm{M}, \mathrm{M} \pm \mathrm{SD})$ 중 가족탄력성 값이 .676(M+1SD)에서 유의하였다. 또한 [그림 1]을 보면, 가족탄력성이 높은 집단이 낮은 집단이나 중간인 집단에 비해서는 삶 만족도가 높다. 그런데, 가족탄력성이 낮은 집단이나 중간인 집단의 경우에는 코로나 불안감에 따라서 삶 만족도의 변화가 크지 않으나, 가족탄력성이 높은 집단의 경우에는 코로나 불안감이 높을수록 오히려 삶 만족도가 급격하게 떨어지는 것으로 나타났다. 즉, 가족탄력성이 높은 집단일 경우, 코로나 불안감이 삶 만족도에 미치는 부정적인 영향력이 더 커졌다.

[표 2] 가족탄력성의 조절효과

[Table 2] The Moderating Effect of Family Resilience ( $\mathrm{n}=216)$

\begin{tabular}{ccccccc}
\hline \multicolumn{7}{c}{ 종속변수: 삶 만족도 } \\
변수들 & Coeffect & $\mathrm{SE}$ & $\mathrm{t}$ 값 & $p$ & LLCI $^{*}$ & ULCI $^{* *}$ \\
\hline 상수 & 3.269 & .046 & 70.905 & .000 & 3.178 & 3.360 \\
\hline 코로나 불안감 & -.065 & .061 & -1.056 & .292 & -.185 & .056 \\
\hline 가족탄력성 & .629 & .069 & 9.168 & .000 & .494 & .765 \\
\hline 코로나 불안감 $\times$ 가족탄력성 & -.160 & .080 & -2.003 & .046 & -.317 & -.003 \\
\hline
\end{tabular}




\begin{tabular}{|c|c|c|c|c|c|c|}
\hline \multicolumn{7}{|c|}{$\mathrm{R}^{2}=.289, \mathrm{~F}=28.708, \mathrm{p}=.000$} \\
\hline \multicolumn{7}{|c|}{ 상호작용에 따른 $R^{2}$ 증가 } \\
\hline 상호작 & \multicolumn{3}{|c|}{$R^{2}$} & $\mathrm{~F}$ & \multicolumn{2}{|r|}{$p$} \\
\hline 코로나 불안감 & \multicolumn{3}{|c|}{.031} & 4.012 & \multicolumn{2}{|r|}{.046} \\
\hline \multicolumn{7}{|c|}{ 가족탄력성에 따른 코로나 불안감의 조건부 효과 } \\
\hline 가족탄력성 & Effect & se & $\mathrm{t}$ 값 & $p$ & LLCI* $^{*}$ & $\mathrm{ULCI}^{* *}$ \\
\hline$-.676(\mathrm{M}-1 \mathrm{SD})$ & .043 & .080 & .541 & .589 & -.115 & .202 \\
\hline $.000(\mathrm{M})$ & -.065 & .061 & -1.056 & .292 & -.185 & .056 \\
\hline $.676(\mathrm{M}+1 \mathrm{SD})$ & -.173 & .083 & -2.083 & .038 & -.336 & -.009 \\
\hline
\end{tabular}

*LLCI=boot 간접효과의 $95 \%$ 신뢰구간 내에서의 하한 값

**ULCI=boot 간접효과의 $95 \%$ 신뢰구간 내에서의 상한 값

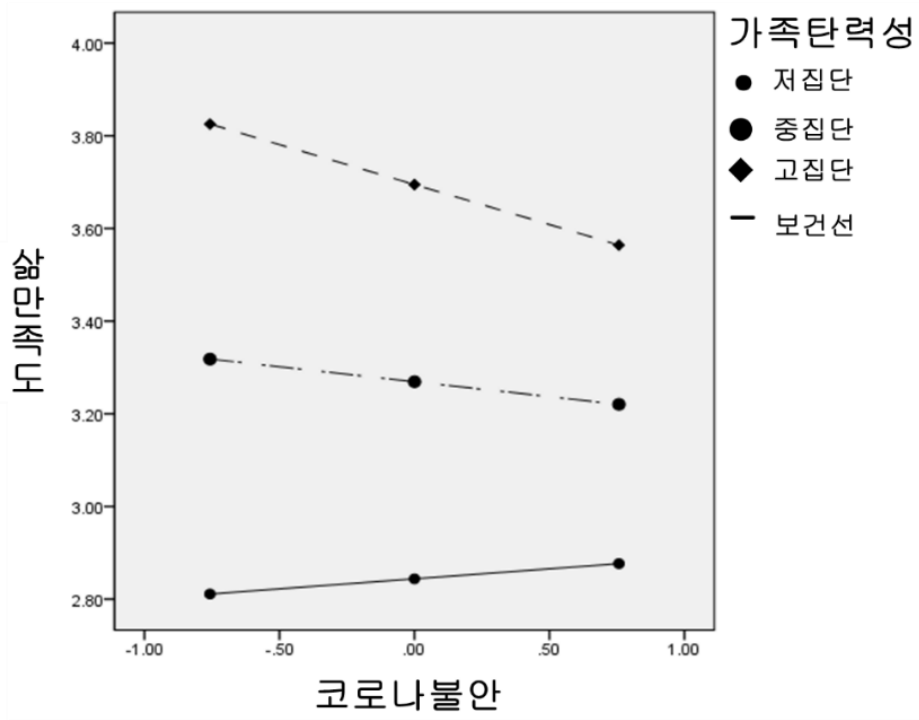

[그림 1] 가족탄력성의 조절효과

[Fig. 1] The Moderating Effect of Family Resilience

\section{2 코로나 불안감이 삶 만족도에 미치는 영향에서 가족친밀감의 조절효과}

가족친밀감이 코로나 불안감과 삶 만족도간의 관계를 조절하는지 분석한 결과, 코로나 불안감과 가족친밀감의 상호작용항의 효과 값이 $-.220(\mathrm{p}=.000)$ 로 유의미하였다. 또한 상호작용항이 추가됨에 따라 R2 변화량은 .058( $\mathrm{p=} .000)$ 로 유의미하여, 가족친밀감의 조절효과가 검증되었다[표 3]. [표 3]의 조건부 효과를 보면, 가족친밀감의 세 가지 조건 $(\mathrm{M}, \mathrm{M} \pm \mathrm{SD})$ 중 가족친밀감 값이 .789(M+1SD)에서 유의하였다. [그림 2]를 보면 가족친밀감이 낮은 집단이나 중간인 집단의 경우에는 코로나 불안감에 따라서 삶 만족도의 변화의 폭이 크지 않으나, 가족친밀감이 높은 집단의 경우에는 코로나 불안감이 높을수록 삶 만족도가 낮아지는 폭이 좀 더 큰 경향으로 나타났다. 즉, 가족친밀감이 높은 집단일 경우, 코로나 불안감이 삶 만족도에 미치는 부정적 영향력이 더 커지는 것으로 나타났다. 
[표 3] 가족친밀감의 조절효과

[Table 3] The Moderating Effect of Family Intimacy $(n=216)$

\begin{tabular}{|c|c|c|c|c|c|c|c|}
\hline \multicolumn{8}{|c|}{ 종속변수: 삶 만족도 } \\
\hline \multicolumn{2}{|c|}{ 변수들 } & Coeffect & SE & $\mathrm{t}$ 값 & $p$ & LLCI* $^{*}$ & $\mathrm{ULCI}^{* *}$ \\
\hline \multicolumn{2}{|c|}{ 상수 } & 3.278 & .048 & 67.937 & .000 & 3.183 & 3.374 \\
\hline \multicolumn{2}{|c|}{ 코로나 불안감 } & -.094 & .065 & -1.444 & .150 & -.223 & .034 \\
\hline \multicolumn{2}{|c|}{ 가족친밀감 } & .385 & .062 & 6.225 & .000 & .263 & .507 \\
\hline \multicolumn{2}{|c|}{ 코로나 불안감×가족친밀감 } & -.220 & .056 & -3.966 & .000 & -.329 & -.111 \\
\hline \multicolumn{8}{|c|}{$R^{2}=.219, \quad \mathrm{~F}=19.779, \mathrm{p}=.000$} \\
\hline \multicolumn{8}{|c|}{ 상호작용에 따른 $R^{2}$ 증가 } \\
\hline \multicolumn{2}{|c|}{ 상호작용 항 } & \multicolumn{2}{|c|}{$R^{2}$} & \multicolumn{2}{|l|}{$\mathrm{F}$} & \multicolumn{2}{|r|}{$p$} \\
\hline 코로나 불안감 & 친밀감 & \multicolumn{2}{|c|}{.058} & \multicolumn{2}{|c|}{15.726} & \multicolumn{2}{|r|}{.000} \\
\hline \multicolumn{8}{|c|}{ 가족친밀감에 따른 코로나 불안감의 조건부 효과 } \\
\hline 가족 친밀감 & Effect & se & t값 & $p$ & & LLCI* $^{*}$ & ULCI** \\
\hline$-.789(\mathrm{M}-1 \mathrm{SD})$ & .079 & .072 & 1.102 & .272 & & -.063 & .222 \\
\hline $.000(\mathrm{M})$ & -.094 & .065 & -1.444 & .150 & & -223 & .034 \\
\hline $.789(\mathrm{M}+1 \mathrm{SD})$ & -.268 & .084 & -3.175 & .002 & & -.434 & -.102 \\
\hline
\end{tabular}

"LLCI=boot 간접효과의 $95 \%$ 신뢰구간 내에서의 하한 값

**ULCI=boot 간접효과의 $95 \%$ 신뢰구간 내에서의 상한 값

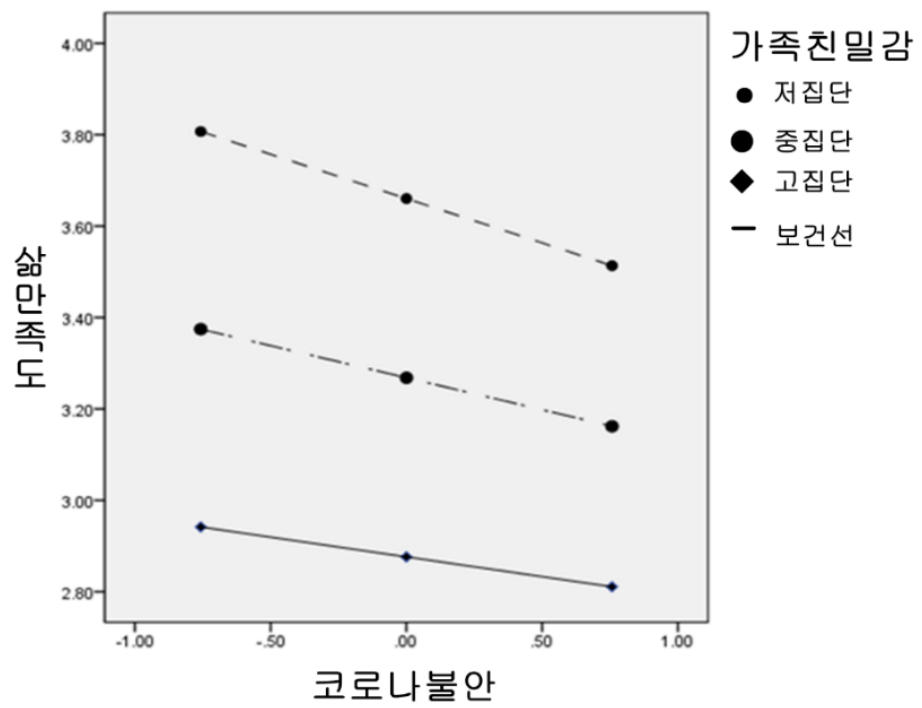

[그림 2] 가족친밀감의 조절효과

[Fig. 2] The Moderating Effect of Family Intimacy

\section{3 코로나 불안감이 삶 만족도에 미치는 영향에서 가족경제적 안정의 조절효과}

가족경제적 안정이 코로나 불안감과 삶 만족도간의 관계를 조절하는지 분석한 결과, 코로나 불안감과 가족경제적 안정의 상호작용항의 효과 값이 $-.142(\mathrm{p}<.01)$ 로 
유의미하였다. 또한 상호작용항이 추가됨에 따라 R2 변화량은 .023( $\mathrm{p}<.01)$ 로 유의미하여, 가족경제적 안정의 조절효과가 검증되었다[표 3]. [표 3]의 조건부 효과를 보면, 가족 경제적 안정의 세 가지 조건 $(\mathrm{M}, \mathrm{M} \pm \mathrm{SD})$ 중 가족 경제적 안정 값이 .840(M+1SD)에서만 유의하였다. 또한 [그림 3]을 보면, 가족 경제적 안정이 높은 집단의 경우에는 코로나 불안감이 높을수록 오히려 삶 만족도가 급격하게 떨어지는 것으로 나타났다. 즉, 가족 경제적 안정이 높은 집단일 경우, 코로나 불안감이 삶 만족도에 미치는 부정적인 영향력이 더 커지는 것으로 나타났다.

[표 3] 가족경제적 안정의 조절효과

[Table 3] The Moderating Effect of Fmily Eonomic Sability ( $n=216)$

\begin{tabular}{|c|c|c|c|c|c|c|}
\hline \multicolumn{7}{|c|}{ 종속변수: 삶 만족도 } \\
\hline 변수들 & Coeffect & $\mathrm{SE}$ & $\mathrm{t}$ 값 & $p$ & LLCI $^{*}$ & $\mathrm{ULCI}^{* *}$ \\
\hline 상수 & 3.263 & .045 & 73.312 & .000 & 3.175 & 3.351 \\
\hline 코로나 불안감 & -.046 & .060 & -.761 & .447 & -.164 & .072 \\
\hline 가족경제적 안정 & .504 & .053 & 9.424 & .000 & .398 & .609 \\
\hline 코로나 불안감 $\times$ 가족경제적 안정 & -.142 & .050 & -2.859 & .004 & -.240 & -.044 \\
\hline \multicolumn{7}{|c|}{$R^{2}=.329, \mathrm{~F}=34.623, \mathrm{p}=.000$} \\
\hline \multicolumn{7}{|c|}{ 상호작용에 따른 $R^{2}$ 증가 } \\
\hline 상호작용 항 & \multicolumn{2}{|c|}{$R^{2}$} & \multicolumn{2}{|c|}{$\mathrm{F}$} & \multicolumn{2}{|r|}{$p$} \\
\hline 코로나 불안감 $\times$ 가족경제적 안정 & \multicolumn{2}{|c|}{.026} & \multicolumn{2}{|c|}{8.174} & \multicolumn{2}{|r|}{.004} \\
\hline \multicolumn{7}{|c|}{ 가족경제적 안정에 따른 코로나 불안감의 조건부 효과 } \\
\hline 가족경제적 안정 & se & & & & LLCI* $^{*}$ & ULCI $^{* *}$ \\
\hline$-.840(\mathrm{M}-1 \mathrm{SD})$ & 067 & 1. & & & -.058 & .206 \\
\hline $.000(\mathrm{M})$ & .060 & - . & & & -.164 & .072 \\
\hline $.840(\mathrm{M}+1 \mathrm{SD})$ & .079 & -2 . & & & -.320 & -.010 \\
\hline
\end{tabular}

${ }^{*} \mathrm{LLCI}=$ boot 간접효과의 $95 \%$ 신뢰구간 내에서의 하한 값

${ }^{* *} \mathrm{ULCI}=$ boot 간접효과의 $95 \%$ 신뢰구간 내에서의 상한 값

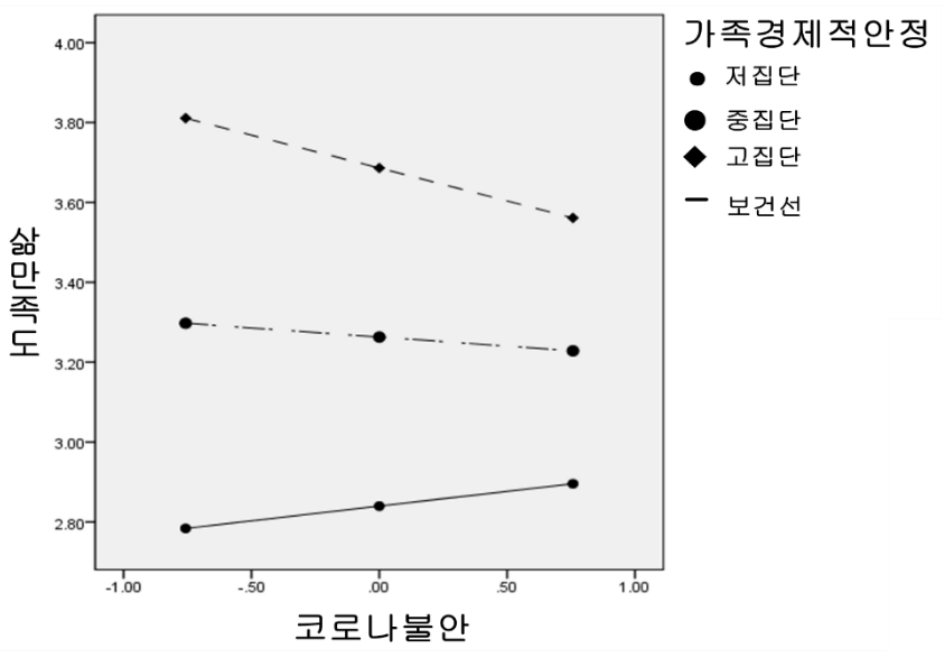

[그림 3] 가족경제적 안정의 조절효과

[Fig. 3] The Moderating Effect of Fmily Eonomic Sability 


\section{4 코로나 불안감이 삶 만족도에 미치는 영향에서 가족문화와 사회참여의 조절효과}

가족문화와 사회참여가 코로나 불안감과 삶 만족도간의 관계를 조절하는지 분석한 결과, 코로나 불안감과 가족문화와 사회참여 상호작용항의 효과 값이 .141(p<.05)로 유의미하였다. 또한 상호작용항이 추가됨에 따라 R2 변화량은 .016( $\mathrm{p}<.05)$ 로 유의미하여, 가족문화와 사회참여의 조절효과가 검증되었다[표 4]. 조절변인인 가족문화와 사회참여의 조건 값에 따른 독립변인인 코로나 불안감의 조건부 효과를 분석한 결과, 가족문화와 사회참여의 세 가지 조건(M, $\mathrm{M} \pm \mathrm{SD})$ 에 따른 결과는 유의하지 않았다[표 4]. 따라서 이 부분은 [그림 4]에 근거해서 설명을 하겠다. '가족문화와 사회참여가 낮은 집단' 은 코로나 불안감이 높을수록 삶 만족도가 낮아지고, '가족문화와 사회참여가 높은 집단' 은 코로나 불안감이 높아져도 삶 만족도가 높아지는 것을 알 수 있다[그림 4]. 즉, '가족문화와 사회참여가 높은 집단' 에서는 코로나 불안감이 삶 만족도에 미치는 부정적 영향이 '가족문화와 사회참여' 로 완화되는 것을 확인할 수 있었다.

[표 4] 가족문화와 사회참여의 조절효과

[Table 4] The Moderating Effect of Fmily Culture and Social Participation (n=216)

\begin{tabular}{ccccccc}
\hline \multicolumn{7}{c}{ 종속변수: 삶 만족도 } \\
변수들 & Coeffect & $\mathrm{SE}$ & $\mathrm{t}$ 값 & $\mathrm{p}$ & LLCI* & ULCI** \\
\hline 상수 & 3.262 & .048 & 68.037 & .000 & 3.168 & 3.357 \\
\hline 코로나 불안감 & -.006 & .067 & -.097 & .923 & -.138 & .125 \\
\hline 가족문화와 사회참여 & .434 & .059 & 7.310 & .000 & .317 & .550 \\
\hline 코로나 불안감 $\times$ 가족문화와 사회참여 & .141 & 067 & 2.096 & .037 & .008 & .273 \\
\hline
\end{tabular}

$\mathrm{R} 2=.221, \mathrm{~F}=20.080, \mathrm{p}=.000$

상호작용에 따른 $\mathrm{R} 2$ 증가

\begin{tabular}{cccc}
\hline 상호작용 항 & $\mathrm{R} 2$ & $\mathrm{~F}$ & $\mathrm{p}$ \\
\hline 코로나 불안감 $\times$ 가족문화와 사회참여 & .016 & 4.393 & .037 \\
\hline
\end{tabular}

가족문화와 사회참여에 따른 코로나 불안감의 조건부 효과

\begin{tabular}{ccccccc}
\hline 가족문화와 사회참여 & Effect & $\mathrm{se}$ & $\mathrm{t}$ 값 & $\mathrm{p}$ & $\mathrm{LLCI} *$ & ULCI** \\
\hline$-.813(\mathrm{M}-1 \mathrm{SD})$ & -.121 & .098 & -1.236 & .218 & -.314 & .072 \\
\hline $.000(\mathrm{M})$ & -.006 & .067 & -.097 & .923 & -.138 & .125 \\
\hline $.813 \mathrm{M}+1 \mathrm{SD})$ & .108 & .072 & 1.491 & .138 & -.035 & .251 \\
\hline
\end{tabular}

*LLCI=boot 간접효과의 $95 \%$ 신뢰구간 내에서의 하한 값

**ULCI=boot 간접효과의 $95 \%$ 신뢰구간 내에서의 상한 값 


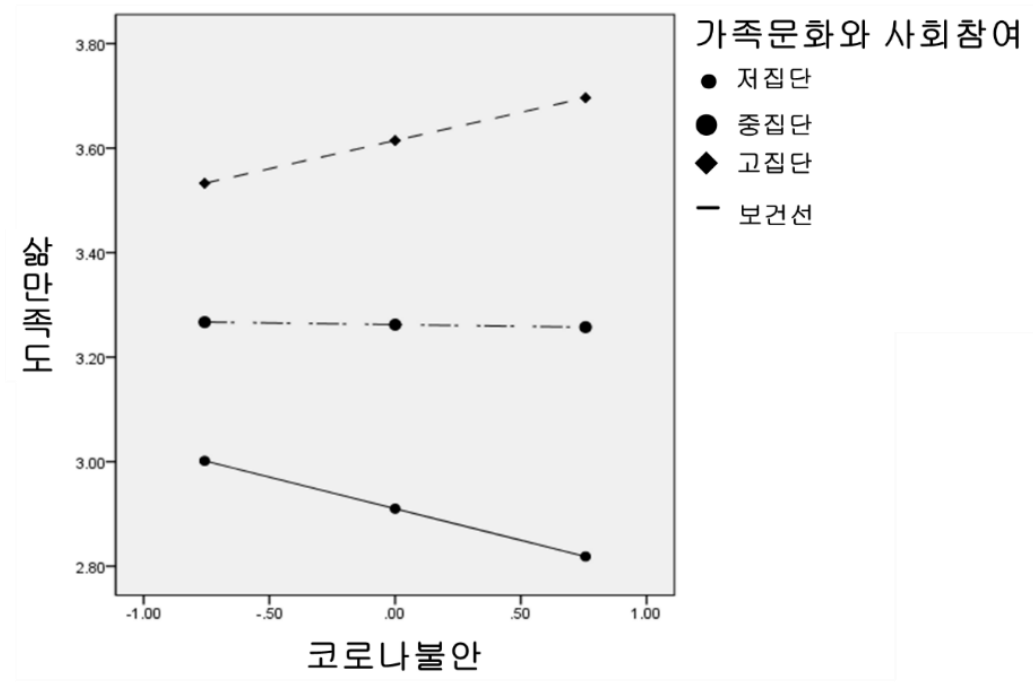

[그림 4] 가족문화와 사회참여의 조절효과

[Fig. 4] The Moderating Effect of Fmily Culture and Social Participation

\section{4. 논의 및 제언}

본 연구의 연구결과를 바탕으로 논의 및 포스트 코로나 시대의 가족복지 정책을 위한 제언을 하고자 한다.

첫째, 가족탄력성이 높은 집단에서 코로나 불안이 높을 때 삶의 만족이 낮아졌다. 코로나19로 인해 비자발적으로 많은 시간을 가정 안에서 가족과 함께 보내야 하는 시간이 길어지는 상황에서, 가족 탄력성이 높은 가족들은 코로나 불안감 등에 대해 서로 대화를 자주 하게 되고, 반복된 대화로 인해 코로나 불안감이 증폭되었을 가능성이 있다. 이러한 불안감으로 삶의 만족도는 떨어졌을 것으로 해석된다. 또한 가족탄력성이 삶의 만족에 미치는 영향을 가족들의 의사소통이 매개할 가능성에 대한 선행연구결과[18] 에서 처럼 가족들의 의사소통 방식에 따라 영향을 미쳤을 가능성도 있다.

둘째, 가족친밀감이 높은 집단의 경우도 코로나 불안이 높을수록 삶의 만족에 미치는 부정적 영향력이 더 커지는 것으로 나타났다. 코로나 19의 장기화로 가족친밀감이 높은 가족의 경우, 코로나 불안이 높을수록 외부와의 접촉을 줄이고 가족중심의 활동이 증가될 가능성이 높다. 높은 가족친밀감은 강요된 친밀감으로 이어질 가능성이 높아 삶의 만족도를 떨어트렸을 가능성이 있다. 또한 높은 가족친밀감으로 가족구성원간 분화수준이 낮아지게 되는 경우, 가족 구성원 개인의 위기나 불안감이 가족 전체에 영향을 미치며 부적 감정을 전이 시킬 수 있다[19]. 더 나아가 이러한 연구결과는 연구대상자들이 여성들이기 때문으로도 생각해 볼 수 있다. 코로나 19이후 가족은

'과부하의 공간' 이 되었고 증가된 가사노동과 자녀돌봄의 부담이 여성들에게로 전가되어졌다는 선행연구[10]과 같이 늘어난 가족활동에 따른 가사노동이나 돌봄의 부담이 삶의 만족도를 떨어트렸을 것으로도 해석된다.

셋째, 가족경제적 안정이 높은 집단의 경우 코로나 불안이 높을수록 삶의 만족이 낮아지고 가족경제적 안정이 낮은 집단의 경우는 코로나불안이 높을수록 삶의 만족이 
높아지는 결과가 나타났다. 가족경제적 안정이 높은 집단의 경우, 이는 '미래의 경제적 안정을 준비하거나 여가문화생활을 할 만한 경제적 여유가 있지만' 코로나 19 에 대한 불안으로 미래의 경제적 안정도 불확실해지고 코로나 이전에 즐기던 여가생활을 할 수 없는 집단의 삶의 만족도가 낮아진 것으로 해석 할 수 있다.

넷째, 가족문화와 사회참여가 코로나 불안감과 삶 만족도 간의 관계를 조절하는지 분석한 결과에서는, 가족문화와 사회참여가 코로나 불안감이 삶의 만족도에 미치는 부정적 영향을 완충하는 것으로 나타났다. 즉, 가족문화와 사회참여가 높은 집단은 코로나 불안감이 삶 만족도에 미치는 부정적 영향이 가족문화와 사회참여로 완화되었다. 코로나 이후 가장 큰 사회적 변화는 방역을 위한 물리적 거리두기의 강화로, 개인과 가족은 사회적 단절 및 고립감을 경험하게 되었다는 것이다. 그럼에도 인간은 혼자서는 살 수 없는 존재이고 지역사회 참여를 통해 다양한 이익을 얻고 소외감을 극복할 수 있으며 나아가서는 자기실현과 성장에 많은 도움을 얻을 수 있기 때문에[20], 사회 공동체성을 회복하는 것이 코로나 불안감을 극복할 수 있는 하나의 방안임이 드러났다. 공동체 의식과 관련된 연구들은 부정적 정서 완화효과, 만성 스트레스 완충효과[21], 그리고 정신적 외상 경감효과[22] 등의 긍정적 효과를 입증하고 있으며, 이는 공동체 의식이 코로나 19 와 같이 지역 내 만연한 부적 스트레스를 완화하는 효과를 가질 수 있음을 시사하고 있다. 따라서 가족들의 고유한 가족문화 형성과 사회참여를 활성화 할수 있도록 공동체 의식 함양을 위한 범사회적 코로나 극복 캠페인과 다양한 매체를 통한 참여 프로그램 확대가 필요하다.

마지막으로, 본 연구의 조사대상자의 표집에 있어서 충청남도의 일부지역에서 유의 표집을 한점과 최종 분석에서 여성만을 분석하여 표본의 대표성에 제한점이 있었다. 그러므로 후속연구에서는 이러한 한계를 극복할 수 있도록 전국적인 표집 단위의 연구가 이루어지기를 기대한다.

\section{References}

[1] E. Y. Jang, A Preliminary Study on the Relationship between Anxiety and Sleep Experience during the COVID-19 Period: Focus on Adults in P City, Korean Journal of Health Psychology, (2021), Vol.26, No.1, pp.73-89, DOI: 10.17315/kjhp.2021.26.1.005

[2] J. Torales, M. O'Higgins, J. M. Castaldelli-Maia, A. Ventriglio, The outbreak of COVID-19 coronavirus and its impact on global mental health, International Journal of Social Psychiatry, (2020), Vol.66, No.4, pp.317-320, DOI: $10.1177 / 0020764020915212$

[3] https://www.gri.re.kr/\%ec\%9d\%b4\%ec\%8a\%88-\%ec\%a7\%84\%eb\%8b\%a8/?brno=14700\&prno=20210166, Apr 16 (2021)

[4] R. Rossi, V. Socci, D. Talevi, S. Mensi, C. Niolu, F. Pacitti, A. Di Marco, A. Rossi, A. Siracusano, G. Di Lorenzo, COVID-19 pandemic and lockdown measures impact on mental health among the general population in Italy, Frontiers in psychiatry, (2020), Vol.11, p.790, DOI: 10.3389/fpsyt.2020.00790

[5] P. Christoph, B. Sanja, P. Thomas, The effect of age, gender, income, work, and physical activity on mental health during coronavirus disease (COVID-19) lockdown in Austria, Journal of Psychosomatic Research, (2020), Vol.139, pp.110186, DOI: https://doi.org/10.1016/j.jpsychores.2020.110278

[6] A. Main, Q. Zhou, Y. Ma, L. J. Luecken, X. Liu, Relations of SARS-related stressors and coping to Chinese college students' psychological adjustment during the 2003 Beijing SARS epidemic, Journal of Counseling Psychology, (2011), Vol.58, No.3, pp.410-423, DOI: http://dx.doi.org/10.1037/a0023632 
[7] D. H. Lee, Y. J. Kim, D. H. Lee, H. H. Whang, S. G. Nam, J. Y. Kim, The Influence of Public Fear, and Psycho-social Experiences during the Coronavirus Disease 2019(COVID-19) Pandemic on Depression and Anxiety in South Korea, Korean Journal of Counseling and Psychotherapy, (2020), Vol.32, No.4, pp.2119-2156, DOI: 10.23844/kjcp.2020.11.32.4.2119

[8] Mirjam A.G Sprangers, Carolyn E Schwartz, Integrating response shift into health-related quality of life research: a theoretical model, Social Science \& Medicine, (1999), Vol.48, No.11, pp.1507-1515, DOI: 10.1016/S02779536(99)00045-3

[9] H. J. Jung, An Analysis of Pathways from Family Stress and Family Adaptation to the Social Adaptation of Autistic Children - Verification of the moderating effect of family resilienc, Korean Journal of Family Welfare, (2009), Vol.13, No.3, pp.89-110, UCI: G704-001932.2008.13.3.005

[10] M. J. Chin, M. A. Sung, S. H. Son, J. E. Yoo, J. L. Lee, Y. E. Chang, Changes in Family Life and Relationships during the COVID-19 Pandemic and their Associations with Perceived Stress, Family and Evionment Research, (2020), Vol.58, No.3, pp.447-461, DOI: 10.6115/fer.2020.032

[11] 2020 Survey on Families in Dangjin City, Dangjin Healthy Family Support Centers, Unpublished, (2021)

[12] M. Y. Sim, J. L. Kim, S. A. Ahn, Influence of Stress on Family Adaptation of Disabled Family : Focused on the Mediation Effect of Family Strength, The Journal of The Korea Contents Association, (2014), Vol.14, No.4, pp.267276, DOI: 10.5392/JKCA.2014.14.04.267

[13] V. C. Chandu, S. Pachava, V. Vadapalli, Y. Marella, Development and Initial Validation of the COVID-19 Anxiety Scale, Indian Journal of Public Health, (2020), Vol.64, No.6, pp.201-204, DOI: 10.4103/ijph.IJPH_492_20

[14] Selman Repišti, Nikolina Jovanović, Martina Rojnić Kuzman, Sara Medved, Stefan Jerotić, Emina Ribić, Tihana Majstorović, Silvana Markovska Simoska, Ljubisha Novotni, Miloš Milutinović, Biljana Blazevska Stoilkovska, Tamara Radojičić, Ivan Ristić, Mirjana Zebić, Tamara Pemovska, Manuela Russo, How to measure the impact of the COVID-19 pandemic on quality of life: COV19-QoL-the development, reliability and validity of a new scale, Global Psychiatry, (2020), Vol.3, No.2, pp.201-210, DOI: https://doi.org/10.2478/gp-2020-0016

[15] S. Taylor, C. Landry, M. Paluszek, T. A. Fergus, D. McKay, G. J. Asmundson, Development and initial validation of the COVID Stress Scales, Journal of Anxiety Disorders, (2020), Vol.72, p.102232, DOI: 10.1016/j.janxdis.2020.102232

[16] Y. J. Yoo, I. S. Lee, S. K. Kim, H. J. Choi, Development of Korea Family Strengths Scale(KFSS- II ), Journal of Families and Better Life, (2013), Vol.31, No.4, pp.113-129, UCI: G704-000320.2013.31.4.003

[17] E. D. Diener, R. A. Emmons, R. J. Larsen, S. Griffin, The satisfaction with life scale, Journal of personality assessment, (1985), Vol.49, No.1, pp.71-75, DOI: 10.1207/S15327752JPA4901_13

[18] I. S. Song, D. Hong, H. S. Park, The Effects of Family Strength on Happiness as Perceived by College Students, Korean Journal of Family Welfare, (2013), Vol.18, No.4, pp.579-598, DOI: 10.13049/kfwa.2013.18.4.579

[19] A. Stephen Anderson, Ronald M. Sabatelli, The differentiation in the family system scale (difs), American Journal of Family Therapy, (2007), Vol.20, No.1, pp.77-89, DOI: https://doi.org/10.1080/01926189208250878

[20] E. Y. Han, M. K. Kim, Relationship among Sense of Community, Social Activity Participation, and Perception of Neighborhood of Adolescents, Journal of the Korean society of child welfare, (2013), No.43, pp.95-124, UCI: G704000946.2013..43.005

[21] E. Cicognani, L. Pietrantoni, L. Palestini, G. Prati, Emergency Workers' Quality of Life: The protective role of sense of community, efficacy beliefs and coping strategies, Social Indicators Research, (2009), Vol.94, No.3, pp.449-463, DOI: $10.1007 / \mathrm{s} 11205-009-9441-\mathrm{x}$

[22] E. A. Greenfield, N. F. Marks, Sense of Community as a Protective Factor against Long-term Psychological Effects of Childhood Violence, Social Service Review, (2010), Vol.84, No.1, pp.129-147. 